\title{
Delitos económicos: en busca de la sanción eficiente
}

\author{
Economic crimes: in pursuit of the efficient punishment
}

\author{
Diego Hernán Goldman ${ }^{[*]}$
}

\begin{abstract}
Resumen: el objetivo del sistema penal en un Estado de Derecho no es reemplazar la venganza privada, sino prevenir el delito. Sin embargo, esa prevención también debe estar sujeta a principios de racionalidad y proporcionalidad y no puede perseguirse a cualquier precio, dado que en ocasiones el sistema penal puede resultar para la sociedad más costoso que el delito mismo. El análisis económico del derecho brinda herramientas para procurar un sistema penal que contribuya a la maximización del bienestar de la sociedad, optimizando la utilización de los distintos tipos de pena como mecanismo de prevención del delito. En este trabajo efectuaremos un repaso en relación a la aplicación del análisis económico al derecho penal, con especial hincapié en los delitos económicos.
\end{abstract}

Palabras claves: análisis económico del derecho penal, disuasión, delitos económicos.

Abstract: the purpose of the criminal system under a Rule of Law is not to replace private vengeance, but to prevent crime. However, such prevention must also be subject to principles of rationality and proportionality and cannot be pursued at any price, given that sometimes the criminal system can be more costly for society than crime itself. The economic analysis of law provide tools to procure a criminal system that can contribute to the maximization of social welfare, optimizing the use of the different types of punishment as a crime prevention mechanism. In this paper we will review the application of the economic analysis of criminal law, with special emphasis on economic crimes.

Keywords: economic analysis of criminal law, deterrence, economic crimes.

[*] Abogado (Universidad de Buenos Aires). Magíster en Economía y Ciencias Políticas (ESEADE). Docente de posgrado de la Universidad de Palermo. Funcionario de la Administración Federal de Ingresos Públicos de la República Argentina. Ex Director General de Asuntos Jurídicos del Ministerio de Seguridad de la República Argentina. Ex Subsecretario de Asuntos Jurídicos del Ministerio de Seguridad de la República Argentina.

Contacto: goldman.diego@gmail.com 


\section{INTRODUCCIÓN}

La sanción penal —en particular la pena privativa de la libertad-constituye la modalidad más drástica, invasiva y, en ocasiones, violenta de intervención legítima del Derecho en la vida de los individuos. Desde los tiempos de la llustración, uno de los mayores propósitos del Derecho Penal ha consistido, precisamente, en contener el poder punitivo del Estado para que no se transforme en un mero vehículo de los deseos de venganza individuales o colectivos, que arrase con los derechos individuales y los deje a merced de la discrecionalidad de la autoridad o del humor cambiante de la masa.

En pos de tal objetivo, el Derecho Penal ha debido trabajar sobre el concepto de pena para dotarlo de racionalidad, de modo que no constituya un mero instrumento vindicativo, sino que opere como una herramienta orientada a un fin, que no es otro que la prevención del delito. En ese sentido, la pena puede funcionar, en líneas generales, como instrumento de disuasión de los potenciales delincuentes, en la medida en que constituya una amenaza creíble y eficaz respecto de las consecuencias que acarreará la violación de la Ley (prevención general), o bien como medio para evitar que quienes ya han delinquido lo continúen haciendo (prevención especial). En ambos casos, un Derecho Penal propio de un moderno Estado de Derecho debe procurar una adecuación de medio a fin, es decir una proporcionalidad entre la respuesta penal, el daño concreto o potencial generado por el delito y la peligrosidad de los sujetos que se busca disuadir o neutralizar, entendida como la probabilidad de que incurran en las conductas que la norma procura evitar.

Lamentablemente, con frecuencia observamos que las normas penales no están redactadas siguiendo estas ideas de racionalidad y proporcionalidad, sino que suelen estar inspiradas en cuestiones más bien prosaicas, vinculadas al temor más o menos fundado que ciertos hechos violentos despiertan en amplios sectores de la sociedad, al repudio que deter- minadas conductas generan en grupos sociales con capacidad de lobby e incluso a modas doctrinarias que responden a intereses particulares de los propios operadores jurídicos 0 mero snobismo académico.

Ahora bien, si aún consideramos que el Derecho Penal debe tener un contenido racional y no simplemente simbólico, el Análisis Económico del Derecho puede resultar una herramienta sumamente útil para repensar la lógica de las sanciones penales, analizar sus efectos y promover una mayor eficiencia y proporcionalidad de las penas.

En líneas generales, el Análisis Económico del Derecho no es otra cosa que la aplicación de las herramientas de la ciencia económica - en particular la microeconomía - al estudio de las instituciones jurídicas, que permite analizar cuestiones tales como el modo en que las normas afectan los incentivos que tienen los individuos para actuar en distintos campos de la vida social o el modo en que inciden en el bienestar general y la distribución de la riqueza. Al respecto, se ha definido al Análisis Económico del Derecho como «(...) la aplicación de la teoría económica y de los métodos econométricos para examinar la formación, estructura, procesos e influencia de la ley y de las instituciones jurídicas» (Roemer, 1994, pp. 5-6), agregándose que tales herramientas pueden ser aplicadas tanto a las leyes que regulan los mercados explícitos, como a las que atañen a actividades en las que no existen transacciones de mercado propiamente dichas, tales como la responsabilidad por daños extracontractuales o los delitos.

En el caso específico del Derecho Penal, el Análisis Económico estudia cuestiones tales como los mecanismos a través de los cuales las leyes pueden contribuir a prevenir el delito, los costos que implica esa prevención y los costos que representan los delitos para las víctimas y para la sociedad en su conjunto, tratando de brindar herramientas que contribuyan a mejorar la eficiencia del sistema penal. En palabras de uno de los precursores del Análisis 
Económico del Derecho Penal moderno, el objetivo de la disciplina consiste en tratar de responder la pregunta relativa a «...cuántos recursos y cuánto castigo debería ser empleado en hacer cumplir distintos tipos de legislación» (Becker, 1968, p. 170).

Desde ya, el Análisis Económico no es una ciencia que por sí misma pueda brindarnos respuestas a todas las interrogantes que plantean, por ejemplo, disciplinas como la dogmática penal o la criminología. Cuestiones de política criminal, tales como determinar qué tipo de conductas deben ser perseguidas penalmente y cuáles no, resultan en este sentido exógenas al análisis económico, que a lo sumo podrá ayudarnos a comprender los efectos sociales de esas decisiones y brindar parámetros para que éstas resulten eficaces y eficientes. En este sentido, se ha observado que «[a] menos que sepamos si y cuánto desvaloramos una especie particular de conducta, no podemos determinar si vale la pena pagar el costo de disuadir cualquier cantidad particular de ella» (Kahan, 2004, p. 644) ${ }^{[1]}$.

Del mismo modo, el Análisis Económico tampoco constituye una suerte de «calculadora» que permita establecer con precisión la respuesta más adecuada para cada caso, sino un instrumento que nos permitirá orientar esas respuestas de modo que se aproximen lo más posible al ideal. Con todo, no deja de ser un instrumento sumamente útil para evaluar el funcionamiento concreto de las normas penales y guiar las decisiones de política criminal, evidentemente superador de la mera intuición $\mathrm{u}$ «ojo» del juez o el legislador.

Dentro de este contexto, el objetivo del análisis, en esta ocasión, será tratar de brindar pautas y herramientas conceptuales para la evaluación de las normas penales desde la perspectiva de la disuasión, que permitan establecer criterios para la adopción de penas eficientes, en el sentido de procurar niveles adecuados de prevención del delito al menor costo social posible. Por otra parte, el foco estará puesto en los delitos económicos, toda vez que, al estar vinculados primordialmente a la actividad de la empresa, la caracterización de los potenciales delincuentes como sujetos que actúan motivados básicamente por intereses pecuniarios resulta, en líneas generales, más próxima a la realidad, lo que permite que cierta simplificación del análisis no le reste capacidad explicativa ni verosimilitud a sus presupuestos.

Como primer paso del análisis propuesto, comenzaremos por repasar algunas ideas centrales sobre las que reposa el Análisis Económico del Derecho Penal, tales como el rol que juega la pena como elemento de disuasión del delito, los parámetros para evaluar la eficiencia de la política criminal y algunas implicancias de estos conceptos. Posteriormente, reflexionaremos sobre el modo en que dichas nociones resultan aplicables al caso de los delitos económicos, abordando cuestiones tales como la mayor o menor conveniencia de privilegiar las sanciones pecuniarias en dicho ámbito o si el hecho de que la legislación promueva la adopción, por parte de las empresas, de mecanismos internos de prevención del delito, resulta socialmente beneficioso.

\section{LA SANCIÓN COMO ELEMENTO DE DI- SUASIÓN}

La idea de que el delito puede analizarse como consecuencia de acciones individuales guiadas por propósitos racionales y no necesariamente como derivación de desviaciones psicológicas, afectaciones neurológicas o cuestiones sociológicas ${ }^{[2]}$, está presente en la historia del Derecho Penal desde los tiempos

[1] Esa valoración, para el citado autor, es eminentemente política y exógena al análisis económico.

[2] Ello no quiere decir, desde luego, que esas y otras disciplinas científicas no puedan resultar de enorme utilidad para entender y abordar los fenómenos delictivos, sino que, no obstante ello, se pueden extraer 
de Beccaria. Es conocida, al respecto, la fuerte influencia del pensamiento económico en el autor milanés, como lo ilustra su definición de la finalidad de la pena:

El fin, entonces, no es otro que impedirle al reo cometer nuevos daños a sus ciudadanos y alejar a los otros de cometer daños iguales. Se deben elegir, entonces, esas penas y ese método para infligirlas, que, mantenida la proporción, causen una impresión más eficaz y duradera en el ánimo de los hombres, y la menos tormentosa en el cuerpo del reo (Beccaria, 1764/2004, p. 48).

Sin embargo, la elaboración más acabada de una teoría económica del delito debió esperar dos siglos más, hasta la aparición en 1968 del célebre ensayo de Gary Becker titulado "Crime and punishment: an economic approach» (Crimen y castigo: una enfoque económico), donde se plantea abiertamente la idea del delincuente como un «maximizador racional» que actúa en base a incentivos y puede ser disuadido en la medida en que la pena esperada, multiplicada por la probabilidad de su aplicación, impliquen para él un costo superior al beneficio que espera obtener del delito:

Prácticamente todas las diversas teorías coinciden en que, [...] cuando otras variables se mantienen constantes, un incremento en la probabilidad de que una persona sea condenada, o del castigo si es condenada, generalmente disminuirá, quizás sustancialmente, quizás despreciablemente, el número de delitos que ella cometerá. Además, una generalización sostenida comúnmente entre personas con experiencia judicial es que un cambio en la probabilidad tiene un efecto mayor en la cantidad de delitos que un cambio en el castigo, a pesar de que, por lo que puedo decir, ninguna de las teorías más destacadas arroja alguna luz sobre esta relación.
El enfoque adoptado aquí sigue el usual análisis de la elección que hacen los economistas, y asume que una persona cometerá un delito si su utilidad esperada excede la utilidad que podría obtener si usara su tiempo y demás recursos en otras actividades. Algunas personas devienen «criminales», por lo tanto, no porque sus motivaciones básicas difieran de las de otras personas, sino porque sus beneficios y costos son distintos. (Becker, 1968, p. 176)

De lo expuesto, podemos extraer como primera conclusión relevante a los efectos de este trabajo que, para que una persona sea disuadida de cometer un delito, el costo esperado de violar la ley debe ser superior al beneficio esperado de dicha acción. Tengamos en cuenta, al respecto, que la evaluación de costos y beneficios no se efectuará en base a información precisa y objetiva, sino a la estimación subjetiva que el individuo realiza al momento de decidir uno u otro curso de acción, y bien puede subestimar o sobrestimar las ganancias que espera obtener del delito, las posibilidades de ser detectado por las autoridades o la cuantía concreta de la pena que se le aplicará en caso de ser condenado. Por otra parte, si bien el costo esperado del delito puede tener aristas muy diversas, entre las que cabe incluir sus costos materiales (equipos, armas, vehículos necesarios para cometer el delito), psicológicos (culpa, ansiedad, miedo, aversión al riesgo), sociales (desaprobación del entorno, estigmatización) y el costo de oportunidad dado por los ingresos que se dejan de percibir por actividades lícitas que podrían haberse realizado utilizando el tiempo y demás recursos destinados al delito (Eide, 2000), nos enfocaremos principalmente en la probabilidad e intensidad de la pena que son, en definitiva, las variables sobre las que puede incidir el sistema penal. De tal modo, ceteris paribus, tenemos que habrá disuasión del delito cuando la

conclusiones útiles para el análisis y aplicación de las normas penales prescindiendo de tales aportes y enfocándose en el estudio de la acción humana tal como la entiende la economía, es decir como una acción racional orientada a fines. 
probabilidad de la pena (Pp) multiplicada por su intensidad (Ip) sean superiores al beneficio esperado del delito $(\mathrm{Be})$ :

$$
\mathrm{Pp} \text { * } \mathrm{Ip}>\mathrm{Be}
$$

Paralelamente, podemos decir entonces que la disuasión (D) puede ser entendida como equivalente al costo esperado del delito definido previamente:

$$
D=P p \text { * } I p
$$

Más adelante analizaremos las diversas implicancias de este esquema sumamente simplificado de la teoría económica del delito. Antes de proseguir con ello, corresponde efectuar algunas breves reflexiones en relación a los perjuicios que el delito provoca al conjunto de la sociedad, el costo que implica establecer mecanismos de disuasión y el modo en que el sistema penal puede contribuir a la maximización del bienestar general.

\section{EL COSTO SOCIAL DEL DELITO Y LA EFI- CIENCIA COMO OBJETIVO DEL SISTEMA PENAL}

Básicamente, el costo social del delito puede entenderse como la suma de los daños individuales causados por la actividad delictiva (lesiones a bienes tales como la vida, la integridad física, la libertad o el patrimonio de las víctimas) a la que se agrega el temor del resto de los miembros de la sociedad a ser víctimas de un delito (Goldman, 2017, p. $32)^{[3]}$. Frente a este costo social del delito se erige, por su parte, el costo de prevención, dado por la suma de recursos de deben destinarse al funcionamiento de las fuerzas de seguridad, el aparato judicial y el sistema penitenciario (salarios, equipamiento, insumos, infraestructura edilicia, capacitación, etc.) ne- cesarios para alcanzar determinado nivel de disuasión del delito.

El sistema penal resultaría eficiente, en este esquema, en la medida en que ambos costos tiendan a igualarse. ¿Por qué? Porque si el costo social del delito fuera superior al costo de prevención, podría obtenerse una mejora del bienestar general incrementando los recursos destinados a la investigación, juzgamiento y sanción de los crímenes que redundara en una disminución del daño provocado por el delito; mientras que si se diera el caso inverso (costo de prevención superior al costo social del delito) resultaría conveniente disminuir los esfuerzos en prevención, permitiendo cierto incremento en los índices delictivos que, en definitiva, afectarían en menor medida al bienestar general que el gasto desmedido destinado a su disuasión.

Siguiendo el mismo razonamiento, una mejora en la eficiencia de los mecanismos utilizados para la prevención del delito, que permitiera disuadir una mayor cantidad de hechos ilícitos a un costo menor o un cambio en las preferencias de los potenciales delincuentes que tuviera el mismo efecto, conllevarían un incremento del bienestar general, toda vez que permitirían que el costo social del delito y el costo de prevención se igualen en niveles menores. Dicho en otros términos, en esta nueva situación hipotética de equilibrio los índices de criminalidad serían menores, lo que permitiría liberar recursos antes destinados a la prevención del delito a otras actividades socialmente redituables.

En el siguiente gráfico ilustramos estos conceptos, pudiéndose observar que, al reducirse el costo de prevención de $\mathrm{Cp}_{1}$ a $\mathrm{Cp}_{2}$, el equilibro con el costo social del delito (Cs) se verificaría en un punto donde la cantidad de delitos totales es menor:

[3] Desde luego, no pueden ignorarse las dificultades que acarrea la medición y cuantificación del costo social del delito, en particular en lo que atañe al miedo a ser víctima del delito, que incluso no suele tener una relación exacta con las probabilidades reales de victimización. Sin embargo, estas dificultades de orden práctico no obstan a la utilidad conceptual del esquema en términos generales. 
Figura 1

Costo de prevención y costo social del delito

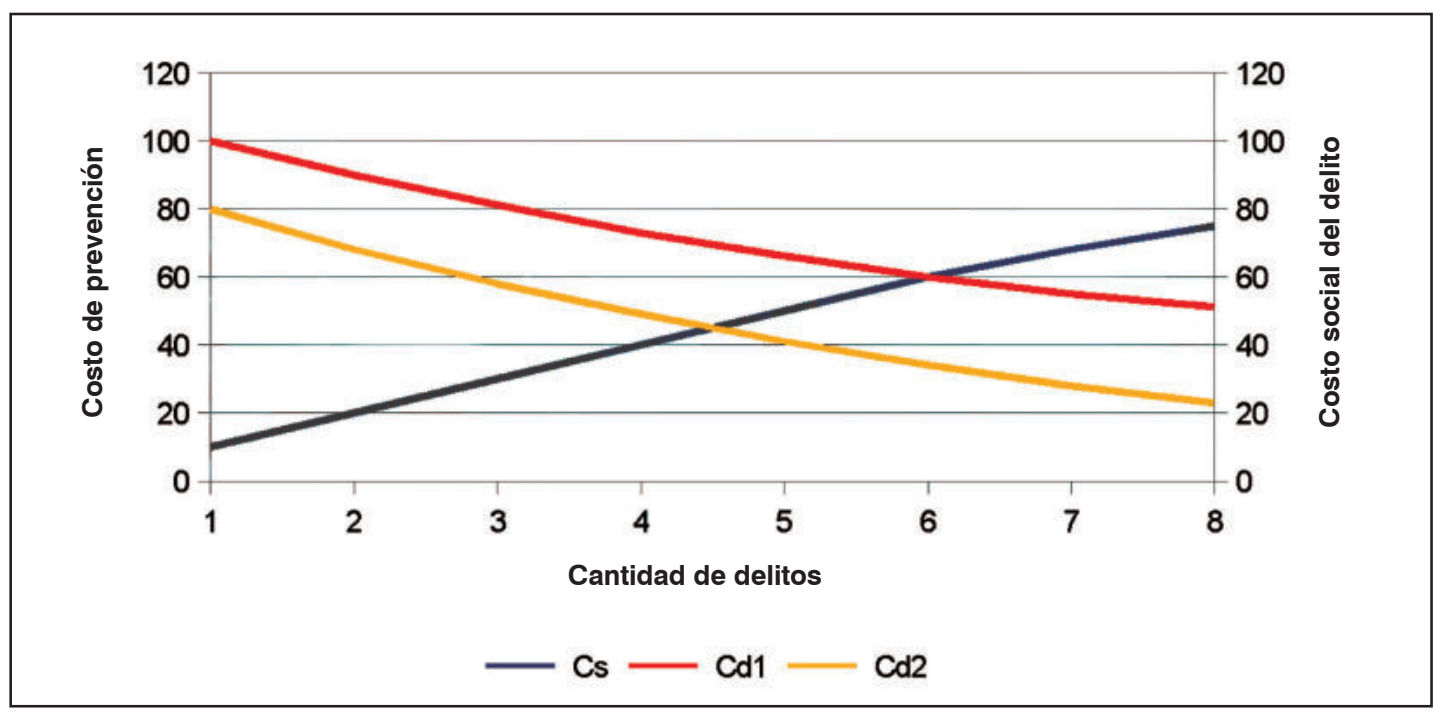

Fuente: Elaboración propia.

Una primer derivación que podemos extraer de lo expuesto es que la política criminal debería tener flexibilidad para adaptarse a cambios en cuestiones tales como la aparición de nuevas tecnologías que facilitan la detección del delito o las preferencias de los individuos, de modo de evitar déficits o excesos en los niveles de disuasión que lleven a una disminución del bienestar general. Estas cuestiones deben ser ponderadas cuidadosamente en cada caso, dado que incluso cambios que a priori pueden parecer beneficiosos, podrían tornarse contraproducentes si no se analizan correctamente sus efectos de mediano o largo plazo. Por ejemplo, la aparición de un nuevo software forense que permita identificar con facilidad a los autores de cierto tipo de delitos, incrementando así la probabilidad de que sea aplicada una pena, podría resultar socialmente perniciosa de no reducirse concomitantemente las escalas penales, si ello lleva a un incremento sustancial de la población carcelaria que a su vez dispara los costos del sistema penitenciario. A continuación profundizaremos algo más sobre estas ideas.

\section{NIVELES DE DISUASIÓN Y SANCIONES EFICIENTES}

Sentado lo que hemos visto en el punto anterior en relación a la conveniencia, en términos de contribución al bienestar general, de encontrar vías para minimizar los costos de prevención del delito, y considerando que la disuasión está —en principio- determinada por la intensidad y probabilidad de la pena, podríamos vernos inclinados a concluir que el sistema penal más eficiente es aquel que, simplemente, eleva las escalas penales tanto como sea posible. Después de todo, incrementar la posibilidad de la pena es socialmente costoso - en la medida que implica dotar de recursos a las fuerzas de seguridad, las fiscalías, los tribunales y al sistema penitenciario-, mientras que incrementar las escalas penales es prácticamente gratuito, y el resultado de la ecuación no variaría operando sobre uno u otro de dichos factores. Sin embargo, existen múltiples razones que impiden arribar a tan sencilla solución.

Más allá de los motivos de orden moral y filosófico que pueden válidamente argüirse 
contra el aumento indiscriminado de las escalas penales — tales como que ello conllevaría la instrumentalización de los individuos penados en pos de objetivos de prevención general, o la necesidad de que las penas guarden una cierta proporción con el daño causado por el delito-, el propio análisis económico nos brinda argumentos adicionales en contra de semejante tentación. Así, en primer lugar, se ha señalado que, toda vez que los distintos delitos ocasionan daños de diversa intensidad a las víctimas y al conjunto de la sociedad, resulta necesario que el sistema penal establezca respuestas diferenciadas para cada uno de ellos en función de su lesividad, puesto que de lo contrario se generarían incentivos para que el individuo que decide delinquir opte siempre por las conductas más graves (en la medida, claro está, que ellas le reditúen un beneficio mayor). Dado que la disuasión absoluta es una utopía irrealizable, el sistema debe al menos concentrarse en desincentivar las conductas más graves, lo que resultaría imposible si todos los delitos fueran amenazados con una sanción máxima:

[...] esto elimina la disuasión marginal, el incentivo para sustituir los delitos más graves por otros menos graves. Si el robo se castiga tan severamente como el homicidio, el ladrón podría igualmente asesinar a su víctima para eliminar un testigo. Por lo tanto, un costo del aumento de la severidad del castigo de un delito es la disminución del incentivo para sustituir con ese delito otro más grave. (Posner, 2007, p. 354)

Desde luego, la necesidad de disuasión marginal de los delitos más graves no constituye, por si misma, un límite suficiente contra el incremento desmedido de las penas, sino que solo conduce a sostener que debe existir una diferenciación entre la pena aplicable a distintos hechos, y que los delitos más graves deben ser sancionados con penas más intensas. Ahora bien, ello no impediría «[...] que el robo se sancione con prisión perpetua, en la medida en que el homicidio se castigue con pena de muerte» (Goldman, 2017, p. 51).

Un segundo argumento que se puede esgrimir en contra de la tentación de utilizar el incremento de las escalas penales como única herramienta para aumentar los niveles de disuasión consiste en señalar que, en rigor, las variaciones en la intensidad y probabilidad de la pena no son perfectamente fungibles en cuanto a sus efectos sobre los índices delictivos. En este sentido, los incrementos en la probabilidad de la pena parecieran tener un efecto disuasivo mayor que el aumento de la intensidad de las penas. Esto podría explicarse bien porque la mayoría de los individuos no son neutrales al riesgo, sino que tienen una aversión a él, lo que potenciaría el efecto de una sanción que se percibe como más probable, o bien por una cuestión de preferencias temporales: las personas tienden a sentirse más intimidadas por una sanción menor, pero más inmediata, que por una mayor pero que estiman lejana (Chalfin y McCrary, 2017. p. 7). El costo que, en términos de estigmatización social y pérdida de oportunidades futuras de empleo, implica de por si el hecho de ser encarcelado, independientemente del plazo de la condena, podría resultar también una explicación factible de este fenómeno en lo que atañe, al menos, a las penas privativas de libertad:

[...] encarcelar a más delincuentes, o encarcelarlos por más tiempo, no es tan efectivo como aumentar el riesgo de aprehensión o condena una vez arrestado. En otras palabras, la actividad delictiva parece ser muy sensible a la posibilidad de arresto y condena, pero menos sensible a la posibilidad o severidad del encarcelamiento. Esto brinda apoyo a la idea de que las consecuencias de ser arrestado y encontrado culpable de un delito penal incluyen las sanciones indirectas impuestas por la sociedad y no solo el castigo impuesto por el sistema de justicia penal. Un individuo condenado puede 
no disfrutar más de las mismas oportunidades en el mercado laboral o del mismo trato por parte de sus pares, por lo que el costo de oportunidad de la pérdida de ingresos y el costo de la estigmatización social para el individuo están implícitos en casos de condena (Bun, Kelaher, Sarafidis y Weatherburn, 2019).

Esta última observación nos puede llevar también a sostener como altamente factible que, en muchos casos, las penas privativas de libertad tengan para el individuo una desutilidad marginal decreciente a lo largo del tiempo, es decir, que el costo que impone el encarcelamiento a la persona condenada se concentre al comienzo del encierro y que, pasado cierto punto, cada año adicional de condena implique un perjuicio cada vez menor. Esta afirmación, que puede resultar quizás contraintuitiva, adquiere mayor sentido si consideramos que los mayores perjuicios para el condenado se producen en los primeros meses o años de prisión: estigmatización, pérdida de otros ingresos y relaciones sociales, angustia derivada del encierro, etc. Con el paso del tiempo, todos esos costos se transforman en «costos hundidos» en los que se incurre una única vez y que no se incrementan en función de la prolongación del encarcelamiento, mientras que los costos subjetivos de la privación de la libertad van disminuyendo con el paso del tiempo por efecto del acostumbramiento. Siguiendo esta lógica, podemos refinar el razonamiento expuesto en el apartado anterior en relación al costo esperado del delito por el individuo, agregando que la intensidad de la pena (lp), para el caso de la prisión, es una función de la desutilidad (De) impuesta por la privación de la libertad y el tiempo de la condena (t):

$$
\mathrm{Ip}=\mathrm{De}{ }^{*} \mathrm{t}
$$

A su vez, si la desutilidad del encarcelamiento resulta decreciente a lo largo del tiempo, para calcular la intensidad total de la pena, el costo subjetivo de cada año adicional de condena debe ser dividido tomando en cuenta la tasa de descuento (Td) de cada individuo. Se ha dicho, en este sentido, que el descuento es un factor potencialmente significativo, dado que muchos criminólogos creen que los delincuentes suelen ser personas más orientadas al presente que la población en general (Polinsky y Shavell, 1997):

$$
I p=D e+D e /(1+T d)+D e /(1+T d)^{2}+\ldots+D e /(1+T d)^{t-1}
$$

De ser correcta, esta idea de la desutilidad marginal decreciente de la pena privativa de libertad nos llevaría a concluir que el efecto de su intensidad, en términos de prevención general, tiene un punto máximo pasado el cual un incremento del plazo de condena ya no produce efectos relevantes, o al menos no efectos que sean suficientes para compensar el costo que implica tener personas encarceladas por un plazo sumamente prolongado de tiempo (Polinsky y Shavell, 2000).

Si todas estas razones no fueran suficientes para concluir que el incremento indiscriminado de las penas no es un modo socialmente eficiente de mejorar la capacidad disuasiva del sistema penal y que, por ende, existe un límite para la intensidad de las sanciones más allá del cual las mejoras de eficiencia en términos de prevención del delito solo se pueden alcanzar trabajando sobre la probabilidad de detección y condena, nos queda revisar un último argumento sobre el punto, vinculado al potencial efecto que penas excesivas pueden tener sobre las actividades lícitas. En efecto, dado que la posibilidad de condenas injustas por error judicial nunca es igual a cero, penas excesivamente severas podrían exponer a individuos que no han cometido delito alguno a un costo significativo, llevándolas a incurrir en cuantiosos gastos destinados a prevenirse de tal posibilidad, o a abandonar actividades lícitas y socialmente útiles que lleven asociado algún nivel de riesgo de vincularse a un proceso penal. Este puede ser el caso, por ejemplo, cuando se impone a las personas jurídicas 
sanciones excesivamente rigurosas por los delitos cometidos por sus miembros o dependientes y se limitan las posibilidades de que el ente ideal se exceptúe de responsabilidad. Aun excluyendo la posibilidad del error judicial, penas muy elevadas para delitos culposos que puedan derivarse de alguna actividad lícita podrían tener idénticos efectos. En palabras de Posner (2007):

Hay una razón relacionada para imponer un tope a los castigos penales de tal modo que no todos los delitos sean disuadidos. Si hay un riesgo de violación accidental del derecho penal (y lo hay, para cualquier delito que implique un elemento de negligencia o de responsabilidad estricta) o del error legal, un castigo muy severo inducirá a las personas a abstenerse de actividades especialmente deseables que se encuentren al borde de la actividad criminal. Por ejemplo, si el castigo por conducir a más de 90 kilómetros por hora fuese la muerte, los individuos conducirían demasiado lentamente (o nada en absoluto) para evitar una violación accidental o una condena por error. (p. 352)

Sentado entonces que la propia eficiencia de las penas exige que se ponga un tope a su intensidad, y que penas excesivamente severas no conllevan necesariamente una mejora de los niveles de disuasión del delito, nos queda analizar qué tipo de sanciones son más eficientes, básicamente distinguiendo entre penas privativas de libertad y penas exclusivamente pecuniarias.

En tal inteligencia, no podemos soslayar, antes de proseguir el análisis, que la pena privativa de libertad no solo debe ser analizada en cuanto herramienta de disuasión (prevención general) del delito, sino fundamentalmente como instrumento de incapacitación (prevención especial) de delincuentes violentos, que no pueden ser neutralizados de otro modo. En rigor, esta función vinculada a evitar la reincidencia prevalece por sobre cualquier otra utilidad que pueda tener el encarcela- miento en ciertos casos, lo que condiciona el análisis en aquellos supuestos en los que la prevención especial del delito resulta una necesidad irrenunciable.

Dicho esto, cabe sostener que, en aquellos casos en los que la naturaleza del delito no hace de por si necesaria la privación de libertad - es decir, básicamente, en los casos de delitos no violentos, que a decir verdad suelen ser mayoría entre aquellos que se encuentran tipificados en los distintos códigos penales-, las sanciones pecuniarias presentan ventajas bastante notorias por sobre el encarcelamiento.

La ventaja más obvia que presentan las multas u otras sanciones pecuniarias en relación a las penas privativas de libertad, es que el costo para hacerlas efectivas es mucho menor. Tal como lo señalaba Becker (1968), mientras que el encarcelamiento insume cuantiosos recursos de la sociedad en la forma de prisiones, guardianes, sistemas de seguridad e, inclusive, el propio tiempo de los reclusos, las multas constituyen meras transferencias de dinero cuyo costo, en términos agregados, es prácticamente insignificante.

En segundo lugar, resulta mucho más sencillo estimar el monto de la sanción eficiente cuando se trata de multas que cuando se trata de penas privativas de libertad, máxime cuando se trata de delitos de contenido económico. Bastaría, en teoría, con establecer la multa en un valor que, multiplicado por la probabilidad de condena, resulte superior al beneficio obtenido del delito. Así, por ejemplo, para disuadir una evasión tributaria de U\$S 1.000 .000 , si la probabilidad de condena fuera del $50 \%$, la multa debería establecerse en una suma que supere los U\$S 2.000.000 e incorpore los costos de investigar el hecho, llevar adelante el proceso y realizar las gestiones de cobro correspondientes. Calcular la pena privativa de libertad eficiente, por el contrario, resultaría bastante más complejo, dado que implicaría tener que analizar el costo subjetivo de la prisión para cada caso concreto, cuestión en la que entran 
a tallar elementos tales como el costo de oportunidad de cada eventual delincuente, sus costos no económicos (estigma social, pérdida de capacidades laborales, angustia por la falta de libertad, etc.) así como la tasa de descuento de la desutilidad que le causa el encarcelamiento a lo largo del tiempo - puesto que, como hemos visto, es probable que la privación de la libertad tenga una desutilidad marginal decreciente- . Respecto de esto último cabe agregar, además, que mientras que en el caso de la pena privativa de libertad es necesario estimar su valor presente, dado que impone al infractor un costo que se distribuye a lo largo del tiempo, la multa por el contrario impone al delincuente un costo que se hace íntegramente efectivo al momento de la condena.

Otro aspecto en el que las penas pecuniarias resultan deseables respecto del encarcelamiento, en particular en casos de delitos no violentos, está relacionado con la probabilidad de reincidencia una vez cumplido el término de la condena. No puede ignorarse, en este sentido, que la pena privativa de libertad reduce las posibilidades laborales lícitas de la persona que fue sometida a ella, y de este modo su costo de oportunidad para reincidir en el delito es mucho más bajo:

El debilitamiento que es relevante aquí no es el causado por el estigma de la condena, que es independiente de la forma específica del castigo (aunque no de su severidad); es el debilitamiento causado por la depreciación de las habilidades, la pérdida de contactos, etc., durante el período del encarcelamiento; en suma, la depreciación del capital humano del condenado. Dado que el ingreso perdido del empleo legítimo es un costo de oportunidad del delito, una disminución de las perspectivas de ingresos legítimos del prisionero disminuye los costos de la actividad criminal para él y por ende aumenta la probabilidad de que cometerá delitos después de su liberación. (Posner, 2007, pp. 355-356)
Una última cuestión que no puede dejar de ponderarse es el hecho de, a diferencia de las penas privativas de libertad — que por imperativos constitucionales y de Derecho Internacional, están siempre condicionadas al desarrollo de un proceso penal rodeado de todas las garantías, en el que la inocencia del imputado es la regla y la apreciación de la prueba sumamente rigurosa-, las multas pueden en algunos casos tipificarse como sanciones de naturaleza administrativa, sometidas a procesos más ágiles y con reglas de imputación menos exigentes. Así, mientras sería impensable una pena privativa de libertad que no tenga como presupuesto la demostración de que ha mediado una acción u omisión culpable del imputado, en el ámbito del Derecho Administrativo sancionador no son extrañas las infracciones que solo dependen de la constatación del incumplimiento objetivo de la normativa - tales como las infracciones imputables a personas jurídicas-, o en las que resulta admisible la inversión de la carga de la prueba en contra del acusado. Ello determina no solo que las multas puedan ser aplicadas mediante procedimientos sensiblemente menos costosos que los necesarios para dictar una condena a prisión, sino que, además, la proporción de sentencias condenatorias suela ser notablemente más alta, lo que implica una probabilidad de castigo muy superior.

Obviamente, los argumentos en favor de las sanciones pecuniarias como herramienta disuasiva de mayor eficiencia en comparación a la pena privativa de libertad se diluyen, tal como lo mencionáramos anteriormente, cuando la finalidad principal de la pena no pasa por la prevención general, sino por la prevención especial o neutralización de delincuentes altamente peligrosos. Está claro, desde este punto de vista, que las multas no resultan sanciones adecuadas -más allá de su posible eficiencia en términos disuasivos - para abordar delitos como los homicidios dolosos, las violaciones o el terrorismo. 
Sin embargo, tal como profundizaremos a continuación, pueden ser instrumentos particularmente óptimos para afrontar la problemática de delitos cuyo contenido es exclusivamente económico, carecen del elemento de violencia que caracteriza a otras formas de criminalidad y en los que, por ende, no prima la necesidad de la prevención especial.

\section{EL EMPRESARIO COMO «MAXIMIZADOR RACIONAL" Y SUS IMPLICANCIAS EN MATERIA PENAL}

El ámbito de la llamada delincuencia económica parece ser, naturalmente, quizás el más fructífero para desarrollar las distintas implicancias de la teoría económica del delito. Si visualizar a un homicida como un sujeto que actúa en función de cálculos de costo-beneficio puede resultar un tanto extraño - lo que no quita que pueda ser un análisis igualmente útil y válido-, lo contrario acontece cuando pensamos en delitos cometidos en el contexto de actividades empresariales, en los cuales las razones para incurrir en conductas contrarias a la ley parecieran ser estrictamente económicas, y en los cuales el sujeto de análisis es el «maximizador racional» por antonomasia: el empresario.

Paralelamente, en materia de delitos económicos las consideraciones relativas a la necesidad de medidas de prevención especial pasan a ser secundarias, o pueden resolverse por vías menos drásticas que el encarcelamiento, -inhabilitaciones, embargos, etc. - mientras que el costo social del delito puede determinarse con mayor facilidad, prácticamente se identifica con el daño concreto causado por el delito: el miedo a ser víctima del delito no resulta un factor de relevancia en el análisis - las personas, en general, no temen ser víctimas de evasores de impuestos, abusadores de información privilegiada o falseadores de balances contables-.

Partiendo de estas premisas, podemos analizar someramente cómo se aplican los conceptos esbozados en los apartados ante- riores a los delitos vinculados con la actividad de las empresas. Nos referiremos en primer lugar al caso de las penas privativas de libertad.

\subsection{Delitos económicos y pena privativa de libertad}

Resulta plausible sostener como hipótesis de trabajo que, para el empresario, la desutilidad del encarcelamiento se puede identificar con el costo de oportunidad por la pérdida de ingresos lícitos que no pueden obtenerse encontrándose en prisión. Ello no quiere decir, nuevamente, que el empresario que se encuentra en prisión no sufra otro perjuicio más que el económico — desde luego, padecerá los mismos costos psicológicos y sociales que cualquier otro individuo-, pero permite simplificar el análisis toda vez que, a diferencia de otros tipos de delitos, los delitos económicos en general están asociados a una actividad lícita que evidentemente se verá resentida por el encarcelamiento y suele ser la principal fuente de ingresos del individuo. Además, la principal motivación para incurrir en esta clase de ilícitos pasa por obtener una ganancia superior a la que se obtendría de una actividad económica completamente lícita, es decir que esa ponderación con el costo de oportunidad estará siempre presente en el proceso volitivo del potencial delincuente.

Una implicancia bastante obvia de esta relación entre el costo de oportunidad y la capacidad disuasiva de la pena privativa de libertad es que los índices de criminalidad económica deberían relacionarse con los niveles de ingreso derivados de actividades lícitas. De hecho, para delitos tales como el robo y el hurto, existe bastante evidencia empírica de que el aumento de los niveles de ingreso conduce a una disminución del delito y viceversa (Chalfin y McCrary, 2017, p. 13). Para los delitos económicos debería mantenerse esa relación, en el sentido de que, si todas las demás variables se mantienen constantes, un incremento en los niveles de ingresos lícitos constituiría un desincentivo para incurrir en conductas ilícitas. Ello 
permitiría mantener idénticos grados de disuasión disminuyendo la intensidad de las penas o la probabilidad del castigo, recordemos, sin embargo, que la reacción ante el cambio de ambas variables no es exactamente idénticalo que equivale a sostener que se reduciría el costo social de la prevención. El equilibrio entre el costo de prevención y el costo social del delito se alcanzaría, entonces, en un nivel de criminalidad menor.

Podría contraargumentarse, sin embargo, que un incremento de los niveles de ingreso conduciría, al mismo tiempo que a un aumento del costo de oportunidad del delito, a mayores beneficios esperados de la actividad ilícita, en la medida en estos constituyan también una función de los ingresos derivados de la actividad lícita de la empresa. Esto parece particularmente cierto, por caso, en el supuesto de los delitos tributarios, en el que el beneficio esperado del delito resulta de multiplicar el ingreso lícito por la alícuota del tributo, por lo que tanto el beneficio como el costo esperado del delito variarían en idéntica proporción, neutralizando cualquier mejora esperable en la disuasión ${ }^{[4]}$. En este caso, si la desutilidad de la pena es igual al ingreso lícito (Ing) no percibido durante el plazo que el condenado permanece en prisión, y el beneficio esperado del delito equivale al ingreso multiplicado por la alícuota del tributo (a), para que haya disuasión tenemos que:

$$
\begin{gathered}
\operatorname{lng} * a<[\operatorname{lng}+\operatorname{lng} /(1+T d) \\
+\operatorname{lng} /(1+T d) 2+\ldots+\operatorname{lng} /(1+T d) t-1] * P p
\end{gathered}
$$

Sin embargo, esa neutralización del mayor efecto disuasivo del costo de oportunidad creciente dada por el incremento proporcional del beneficio esperado del delito no se daría en aquellos casos en que éste último no constituye una función del ingreso lícito. De tal modo, sería esperable que un incremento en los ingresos de los empresarios conduzca a la reducción de la cantidad de delitos que no se relacionan directamente con esas ganancias lícitas, tales como los fraudes contables, el lavado de dinero o el abuso de información privilegiada.

Amén del hecho de que personas con altos ingresos deberían ser, excepto en los casos ya mencionados, más fáciles de disuadir de cometer delitos por su alto costo de oportunidad - a lo que cabría agregar el altísimo costo de la estigmatización en términos de pérdida de relaciones de negocios, vínculos sociales, prestigio profesional, etc.-, otra razón por la cual no resultaría socialmente conveniente el uso de la pena privativa de libertad -o al menos el encarcelamiento por largos períodos de tiempo- está dada por la pérdida del producto de las actividades lícitas que el empresario no puede realizar por estar en prisión.

Si, como sostuvimos anteriormente, el tiempo y demás pérdidas que sufre el propio delincuente no pueden ser dejados de lado al momento de ponderar el costo social de la prevención, aún cuando se trate de personas que realizan principalmente actividades ilícitas, mucho menos puede incurrirse en tal omisión cuando nos referimos a individuos que llevan a cabo actividades mayormente lícitas y socialmente útiles, que generan riqueza, empleo, pagan impuestos y contribuyen al bienestar general. Cabe preguntarse, en este sentido, si incluso en ciertos casos la sociedad no se perjudica más por lo que pierde en términos de contribución a la generación de riqueza al mantener en prisión a una persona altamente productiva, que lo que gana al evitar el costo social de ciertos delitos. Será, en definitiva, una cuestión que deberá ponderarse de conformidad con las características de cada supuesto particular, pero no deja de

[4] Por el contrario, una reducción de la alícuota del tributo disminuiría sustancialmente el costo de la disuasión, al reducir el beneficio esperado del delito tributario. 
resultar un argumento en favor de procurar la disuasión de los delitos económicos por medio de instrumentos socialmente menos costosos que la cárcel.

Lo antedicho nos lleva a evaluar si no resulta en líneas generales más conveniente abordar directamente la problemática de la criminalidad económica por medio de sanciones pecuniarias que a través de las penas privativas de libertad.

\subsection{Análisis de las sanciones pecuniarias}

Más allá de los beneficios apuntados en el capítulo anterior, la pena de multa tiene, en línea con lo que venimos desarrollando, la obvia ventaja de que no impide que el delincuente continúe realizando actividades lícitas por un período de tiempo, eliminando en consecuencia ese componente del cálculo del costo social de la prevención. Se trata de una mera transferencia patrimonial que, a menos que lleve al empresario a la quiebra, no afecta su capacidad productiva. De tal modo, la pena conservaría su función disuasiva, pero evitando una pérdida social adicional en casos en los que la prevención especial por medio de la privación de la libertad resulta innecesaria.

La sanción pecuniaria, cabe insistir, permite una más adecuada graduación de su intensidad a los efectos de alcanzar una disuasión eficiente. Si, para disuadir un acto ilícito, resulta preciso que la sanción esperada sea mayor al beneficio esperado del delito, sería razonable que, en la medida de lo posible, las multas sean expresadas en función de ese beneficio esperado y no como montos fijos desvinculados de las ganancias ilícitas. Idealmente, podrían establecerse las multas como un múltiplo $(x)$ del beneficio esperado del delito tal que, multiplicado por la probabilidad del castigo y agregándose a ese producto los gastos del proceso (Gp), resulte superior al ingreso obtenido del delito:

$$
\left[\left(B e^{*} x\right) * P p\right]+G p>B e
$$

Al no estar definida la proporción en la cual multiplicar el beneficio esperado del delito para fijar la multa, y dado que el incremento en el monto de las sanciones pecuniarias -a diferencia de la privación de libertad — no implica un aumento del costo social de la prevención, podríamos vernos tentados a fijar un múltiplo muy alto, incluso tendiente al infinito. Esto, sin embargo sería un error por varios motivos.

El primero de ellos es que, cubierto el vaIor del beneficio ilícito, el remanente de la multa será abonado con ingresos lícitos. Aún si ello no llevara a la quiebra al infractor, igualmente podría implicar un detrimento innecesario de su patrimonio, desviando recursos hacia el Estado que podrían ser más eficientemente empleados por el empresario para satisfacer las necesidades de otros individuos en el mercado. Se podrá objetar que no siempre el empresario es más eficiente en la producción de bienes y servicios socialmente demandados que el Estado -y seguramente ofrecer ejemplos de organizaciones estatales sumamente eficientes y de empresarios verdaderamente ineficientes-, pero lo cierto es que, en razón de los incentivos con que cuentan unos y otros -que no es del caso tratar aquí- y exceptuando los supuestos de bienes públicos esenciales, los particulares suelen actuar de modo más eficiente que el Estado. Es decir, una multa extremadamente alta podría producir una merma del bienestar social en la medida en que implique una pérdida de eficiencia en la asignación de recursos del conjunto de la economía.

Asimismo, como ya se explicó anteriormente, una multa demasiado alta en relación al beneficio obtenido por el delito —que, además, en los supuestos de criminalidad económica, es prácticamente equiparable al costo social del delito-, elimina la disuasión marginal de los delitos menos graves. Si a un evasor de impuestos se le aplica idéntica multa o se 
lo expone a la quiebra por evadir tanto U\$S 100.000 como U\$S 10.000.000, no tendrá incentivo alguno para tratar de limitar el daño provocado por su accionar ilícito y siempre le resultará conveniente tratar de maximizar la ganancia del delito. Inclusive, cuando las sanciones son aplicadas a personas jurídicas por los actos de sus integrantes o dependientes, una pena tal que exponga a la firma a la quiebra o afecte severamente sus operaciones, eliminaría los incentivos para colaborar con las autoridades y adoptar mecanismos de prevención interna del delito mediante un programa de compliance - a menos, claro está, que esa colaboración le permita eximirse de sanciones- (Hamdani y Klement, 2008), toda vez que esa inversión solo redundaría en mayores posibilidades de que se le terminen aplicando sanciones ruinosas.

Sanciones excesivamente gravosas podrían conducir también a las denominadas «trampas disuasorias» en las que la probabilidad siempre latente de ser sancionado injustamente, recordemos que las sanciones pecuniarias habilitan la posibilidad de su aplicación en sede administrativa, con estándares probatorios y reglas de imputación más laxastermina constituyendo un desincentivo para la realización de actividades lícitas y socialmente útiles, pero que implican un riesgo de producción de daños o de terminar vinculadas con hechos que constituyen infracciones penales o administrativas. Muchas veces, estas actividades potencialmente riesgosas en sentido penal están vinculadas a la introducción de nuevos productos o procesos en áreas como la industria o las finanzas, a las inversiones en capital de riesgo o a la innovación en general, o sea que el exceso de disuasión podría afectar a sectores o actividades capaces de producir grandes incrementos del bienestar general, induciendo a los empresarios a adoptar estrategias demasiado conservadoras o directamente a abandonar mercados o ramas de la actividad económica:
Los directivos tienden a ser conservadores con respecto a hacer nuevas inversiones e introducir nuevos productos porque las consecuencias de una decisión fallida podrían incluir demandas y sanciones penales. Desafortunadamente, este enfoque conservador de los negocios conducirá aún más a una economía lenta y un mercado laboral débil. (Wilda, 2004, p. 685)

Un modo de mejorar las probabilidades de detección y sanción de los delitos que se producen en el marco de las actividades de las empresas, disminuyendo asimismo los costos sociales de la prevención, es promover la colaboración de las propias firmas con el sistema de justicia, induciéndolas a adoptar programas internos de prevención de actos ilícitos vinculados a su giro comercial, mediante la amenaza de sanciones a la persona jurídica en caso de que tales mecanismos no hubieran sido implementados o resultaren ineficaces. La adopción de programas de compliance adecuados a las necesidades de cada empresa puede contribuir a prevenir la criminalidad económica básicamente por dos vías: por un lado, dificultando la comisión de actos ilícitos en el seno de la organización, mediante el establecimiento de reglas, procedimientos y controles internos tendientes a asegurar el cumplimiento de las normas legales en el desarrollo de las actividades de la firma; por el otro, incrementando la posibilidad de que los delitos que igualmente sean cometidos eludiendo esos controles, puedan ser detectados y sancionados:

Estos programas, cuando se encuentran adecuadamente diseñados y aplicados, pueden potenciar el efecto disuasivo respecto de los individuos proclives a cometer actos ilícitos en el contexto de sus funciones en la empresa, al facilitar la detección y sanción de esos desvíos, tanto en la órbita interna de la organización como en el ámbito penal, en la medida en que sean oportunamente denunciados a las autoridades -lo cual suele ser requisito para eximir de sanciones a la persona jurídica- 
y se pongan a su disposición elementos de prueba que permitan su juzgamiento, de difícil obtención de otro modo. (Goldman, 2019, pp. 25-26)

Este incremento en el costo esperado del delito para el potencial infractor, vía la mejora en las probabilidades de detección y castigo, permitiría una sustancial reducción del monto de las sanciones, permitiendo atenuar de tal modo el aparente conflicto entre la necesidad de disuadir el delito y la no afectación de los niveles de actividad económica. En efecto, en aquellos casos en que la propia empresa es la que detecta el hecho y lo pone en conocimiento de las autoridades, la lógica llevaría a eximir de sanciones al ente ideal o restringir su responsabilidad, en todo caso, a la obligación de resarcir el daño en sede civil o administrativa. Del mismo modo, y siempre en aras de promover que las propias empresas se involucren en la prevención de la criminalidad económica, la mera adopción de un programa de compliance apropiado - aunque en el caso concreto no haya podido evitar la comisión del hecho ilícito-, debería servir para eximir o al menos atenuar las sanciones a la persona jurídica. De no contemplarse esta reducción o exención de sanciones, no existiría incentivo para que las empresas colaboren con las autoridades, lo que solo podría redundar en la certeza de la sanción. Más aún, les resultaría económicamente más conveniente tratar de encubrir y ocultar los delitos cometidos por sus directivos o dependientes.

Asimismo, debería siempre procurarse que las exigencias legales no impongan a las empresas la implementación de programas de prevención excesivamente costosos en relación a su patrimonio y capacidad financiera: si el costo del programa de compliance resultara mayor al costo de la sanción esperada, lógicamente el interés de la firma la llevaría a omitir la inversión en prevención y afrontar las eventuales multas o, llegado el caso, directamente abandonar el mercado o actividad en favor de otros menos regulados.
Teniendo en cuenta estas observaciones, la atribución de responsabilidad administrativa a las personas jurídicas por la falta de adopción de mecanismos adecuados de prevención, puede constituir una herramienta sumamente útil para mejorar la eficiencia en la persecución de los delitos económicos, al permitir un incremento en la probabilidad de la pena a un costo generalmente menor. En este sentido, el hecho de que nadie mejor que las propias empresas conoce el modo en que se desarrollan sus negocios, los riesgos potenciales que implican sus actividades y los mecanismos más adecuados para prevenirlos, hace que la utilización de los recursos en pos de la prevención del delito sea más eficiente de lo que podría ser en manos del Estado, que en definitiva no es sino un tercero ajeno a ese giro comercial que desconoce sus particularidades y vericuetos.

\section{CONCLUSIONES}

Tal como hemos visto, en un Estado de Derecho el sistema penal no puede ser un instrumento al servicio de las pasiones humanas pasajeras, sino una herramienta que responda a fines racionales, que no son otros que la prevención del delito. El Análisis Económico del Derecho no solo nos provee de una explicación en relación a cómo las penas sirven a ese propósito preventivo, sino que además nos plantea que el Derecho Penal puede contribuir a maximizar el bienestar de la sociedad. Así, desde esta perspectiva, el objetivo del sistema penal no es eliminar completamente el delito -lo cual implicaría un despilfarro de los siempre escasos recursos de la sociedad en la búsqueda de una utopía inalcanzable - sino focalizarse en aquellos hechos que causan un perjuicio mayor al costo que implica su disuasión. Esto llevaría a una asignación eficiente de los recursos y, en consecuencia, a que se alcancen los máximos niveles de bienestar posibles.

La búsqueda de la eficiencia conlleva la necesidad de recurrir, para la disuasión del delito, a aquellas penas que logren el mayor efec- 
to al menor costo posible. Trayendo la célebre definición de Beccaria al lenguaje del Análisis Económico del Derecho, podemos decir que la sanción eficiente es aquella que permite maximizar la disuasión y minimizar los costos de prevención del delito.

En este sentido, la pena privativa de libertad, si bien resulta irremplazable en aquellos casos en que priman necesidades de prevención especial, en particular respecto de los autores de delitos violentos que no pueden ser neutralizados de otro modo, es un instrumento extremadamente costoso para la sociedad. No sólo por los gastos que implica mantener privada de su libertad a una persona por un período más o menos prolongado de tiempo y por el costo que ese encierro implica para la propia persona condenada - que, en tanto miembro de la sociedad, no puede dejar de ser ponderado-, sino porque implica también la degradación de un capital humano que se ve impedido de realizar actividades socialmente útiles en el presente y merma su capacidad de generar riqueza en el futuro - lo que, a su vez, constituye un incentivo para la reincidencia-. Esto resulta aún más evidente en el caso de los delitos económicos, vinculados por lo general -no siempre, desde luego- a actividades económicas lícitas, en los que privar de su libertad a un empresario, a un profesional o a un trabajador altamente calificado, sin que medien razones de prevención especial para ello, implica coartar la posibilidad de que estos produzcan bienes y servicios demandados por otros individuos, que redundan en un incremento de la riqueza general.

Las sanciones pecuniarias, en este orden de ideas, parecen mucho más adecuadas para afrontar la criminalidad económica que las penas privativas de libertad: pueden aplicarse mediante procedimientos mucho menos costosos y expeditos, con menores exigencias probatorias y procesales -lo que, además, mejora sustancialmente las probabilidades de condena - y la ejecución de las sentencias no exige el mantenimiento de un oneroso sistema penitenciario. Asimismo, pueden graduarse de forma más precisa y adecuada en función del daño causado por el delito y las necesidades puntuales de disuasión. Finalmente, y esto no resulta una cuestión menor en el tipo de actividades que constituyen el objeto del Derecho Penal económico, las sanciones pecuniarias pueden hacerse efectivas sin generar una afectación a la capacidad futura de generación de riqueza de las empresas. Al respecto cabe señalar no sólo el aspecto obvio de que una persona privada de su libertad difícilmente puede generar ingresos lícitos, sino que el efecto estigmatizador de la pena puede incluso afectar letalmente la reputación de la organización en la que esa persona se desempeñaba. En tal sentido, se ha destacado que, en muchos casos, ciertas firmas vinculadas a sectores de la economía en el que la reputación y la confianza son fundamentales - finanzas, auditoría, servicios profesionales- no sólo no podrían continuar funcionando luego de una condena penal, sino que ni siquiera podrían resistir el hecho de verse involucradas en una investigación penal (Hamdani y Klement, 2008, p. 279).

En cuanto al modo de establecer el monto de las sanciones, lo óptimo sería que resulten proporcionales al provecho ilícito obtenido del delito, teniendo en cuenta la probabilidad de la pena y los gastos procesales. Si bien a priori la única exigencia al respecto, además de la proporcionalidad, sería que el monto de la sanción esperada supere al del beneficio esperado del delito - para asegurar el efecto disuasivo de la pena-, debería procurarse que los montos no resulten tan elevados como para llevar a la quiebra tanto a los autores individuales del hecho como a las organizaciones que deban responder por ellos, dado que eso eliminaría la disuasión marginal de los delitos menos graves y los incentivos para adoptar mecanismos internos de prevención del delito.

Finalmente es de resaltar que los regímenes de responsabilidad administrativa de las personas jurídicas por los hechos cometidos por sus directivos o dependientes pueden re- 
sultar de gran utilidad - en la medida en que estén adecuadamente diseñados teniendo en cuenta los incentivos que generan- para que las propias firmas, a través de los programas de compliance, contribuyan a disminuir el costo de prevención del delito y mejorar las probabilidades de aplicación de la ley.

\section{REFERENCIAS}

Beccaria, Cesare (2004). De los delitos y de las penas. (Traducción de Antonio Bonanno). Buenos Aires: Losada. (Originalmente publicado en 1764).

Becker, Gary (1968). «Crime and punishment: an economic approach». Journal of Political Economy, vol. 76, N. ${ }^{\circ}$ 2, University of Chicago, pp. 169-217.

Bun, Maurice; Kelaher, Richard; Sarafidis, Vasilis \& Weatherburn, Don (2019). «Crime, deterrence and punishment revisited». Empirical Economics, Institut für Höhere Studien, https://doi.org/10.1007/s00181-019-01758-6.

Chalfin, Aaron \& McCrary, Justin (2017). «Criminal deterrence: a review of the literature». Journal of Economic Literature, vol. 55, N. ${ }^{\circ}$, American Economic Association, pp. 5-48.

Eide, Erling (2000). «Economics of criminal behavior». En B. Bouckaert y G. De Geest (eds.), Encyclopedia of Law and Economics. Volume V. The economics of crime and litigation (pp. 345389). Cheltenham: Edward Elgar Publishing.

Goldman, Diego (2017). «Análisis económico del Derecho Penal y Derecho Penal Liberal: confluencias y bifurcaciones». Derecho Penal y Criminología, vol. XXXVIII, N. ${ }^{\circ} 104$, Universidad Externado de Colombia, pp. 13-74.
Goldman, Diego (2019). "Compliance y regímenes sancionatorios de las personas jurídicas: algunas consideraciones económicas». Yachaq, N. ${ }^{\circ} 10$, CIED - Universidad Nacional de San Antonio Abad del Cusco, pp. 21-38.

Hamdani, Assaf \& Klement, Alon (2008). «Corporate crime and deterrence». Stanford Law Review, vol. 61, N. ${ }^{\circ}$ 2, Leland Stanford Junior University, pp. 271-310.

Kahan, Dan (2004). «The teory of value dilemma: a critique of the economic analysis of criminal law». Ohio State Journal of Criminal Law, vol. 1:2, Ohio State University, pp. 643-651.

Polinsky, Mitchell \& Shavell, Steven. «On the disutility and discounting of imprisonment and the theory of deterrence». Working paper 6259. National Bureau of Economic Research. http://www.nber.org/papers/w6259.

Polinsky, Mitchell \& Shavell, Steven. «Public enforcement of law». En B. Bouckaert y G. De Geest (eds.), Encyclopedia of Law and Economics. Volume V. The economics of crime and litigation (pp. 307-343). Cheltenham: Edward Elgar Publishing.

Posner, Richard (2007). El análisis económico del Derecho, segunda edición. Traducción de Eduardo Suárez. México D.F.: Fondo de Cultura Económica.

Roemer, Andrés (1994). Introducción al análisis económico del derecho. México D.F..: Fondo de Cultura Económica.

Wilda, Nathan (2004). «David pays for Goliath's mistakes: the costly effect Sarbanes-Oxley has on small companies». The John Marshall Law Review, vol. 38, The John Marshall Law School, pp. 671-692. 